\title{
Arsenic volume estimates in Holocene clay plug sediments in Bihar, India
}

\author{
S. Kumar, M.E. Donselaar \& F. Burgers \\ Department of Applied Geoscience and Engineering, Delft University of Technology, Delft, The Netherlands
}

\begin{abstract}
Shallow aquifers in the densely-populated areas of the Indo-Gangetic plain are severely polluted with arsenic (As). The occurrence of As and its spatial concentration variability are conditioned by the geomorphological setting of the Holocene floodplain, with the highest concentrations in elevated point-bar surrounded by clay-filled oxbow lakes (clay plugs). The work hypothesis is that the As is locally derived from the clay plugs. In this study, the potential As volume in the clay plugs is calculated, and the migration process of arsenic from clay plug to adjacent point bar is studied. Satellite data in combination with a side-scan sonar survey in present-day oxbow lakes, and As concentrations in sediment from a well were used to calculate the sediment volume of the clay plug, the potential volume of As, and the contact area between the clay plug and adjacent point bar, and to estimate the initial diffusion flux of dissolved As from clay plug to the adjacent point bar.
\end{abstract}

\section{INTRODUCTION}

Elevated sandy point bars surrounded by clay-filled oxbow lakes (clay plugs) in Bhojpur and Buxar districts of Bihar (Fig. 1) are hotspots for arsenic (As). Arsenic concentrations in groundwater of the point bars are characterized by a large spatial variation over short distances. Donselaar et al. (2016) proposed a generic model in which As is sourced from the clay plugs surrounding the point bars, and subsequently migrates to the groundwater in the permeable point bar sand. The present paper aims to provide insight in the potential As volume in clay plugs of the Holocene Ganges River floodplain, and to present ideas on the migration processes of As from clay plug to adjacent point bar.

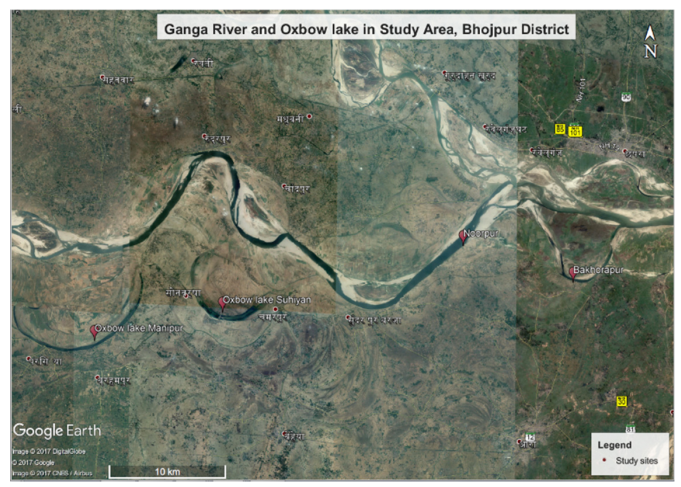

Figure 1. Ganges River and oxbow lakes in the study area.

\section{METHODS}

Clay plug surface areas were mapped with sentinel satellite data and Google Earth-Pro imagery. Clay plug volumes and contact areas between the clay plug and adjacent point bar were calculated in Matlab by combining the surface areas with bathymetric profiles derived from a side-scan sonar survey in recent oxbow lakes along the Ganges River, Bhojpur District in Bihar (Fig. 2). Arsenic concentrations in sediments from a borehole study in Holocene clay plugs in the Haringhata district (West Bengal, India) of Ghosh et al. (2015) were used to calculate As volumes contained in the clay plug deposits.

\section{RESULTS AND DISCUSSION}

\subsection{Calculation of potential arsenic volumes}

Surface areas of the selected clay plugs ranged from $10^{6}$ to $10^{7} \mathrm{~m}^{2}$. Maximum depth of the oxbow lakes

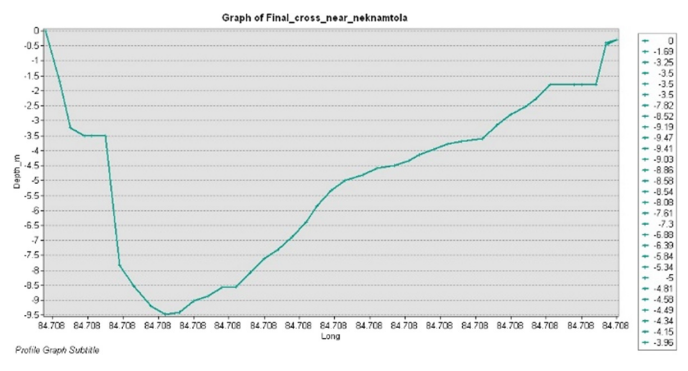

Figure 2. Sonar bathymetric profile of an oxbow lake along the Ganges River in the study area. 
in the bathymetric study was $9.47 \mathrm{~m}$. Arsenic content in cores from wells averaged $17.7 \mathrm{mg} \mathrm{kg}^{-1}$ sediment (Ghosh et al., 2015). The calculated sediment volume of clay plugs ranges from $10^{6}$ to $10^{8} \mathrm{~m}^{3}$. The resultant As volume contained in the clay plug sediment ranges from $10^{5}$ to $10^{6} \mathrm{~kg}$. The contact area between the clay plug and the adjacent point bar was in the order of $10^{6}$ to $10^{7} \mathrm{~m}^{2}$.

\subsection{Estimation of diffusion fluxes}

There are no known driving forces in the point bar for the release of As from its solid state and the concentration of soluble As in the pore fluid of the point bar sands is negligible. The discharge depends linearly on the hydraulic conductivity, this soil property is of large influence over time. The discharge also depends on the present As volume. Over time the volume will decrease and thus the discharge will decrease. The discharge decrease is exponentially over time. Equation (1) describes Fick's first law of diffusion process with two assumptions, firstly that the system must be in steady state, and secondly that the medium must be homogeneous.

$\mathrm{J}=-\mathrm{D} \nabla \mathrm{C}$

$\mathrm{D}$ is the diffusion coefficient, a material specific property, and $\mathrm{C}$ is the concentration. With some modifications Fick's first law for transport through a membrane is given by equation (2)

$\mathrm{J}=\mathrm{K} \nabla \mathrm{C}$

Where $\mathrm{J}$ is diffusion flux $\left[\mathrm{mol} \mathrm{m}^{-2} \mathrm{~s}^{-1}\right], \mathrm{K}$ the hydraulic conductivity of the medium $\left[\mathrm{m} \mathrm{s}^{-1}\right]$ and $\Delta \mathrm{C}$ the difference in concentration $\left[\mathrm{mol} \mathrm{m}^{-3}\right]$. The hydraulic conductivity value, which is crucial to the modified version of Fick's first law, was considered to be within the following range: a minimal value of $10^{-8} \mathrm{~m} \mathrm{~s}^{-1}$ and a maximal value of $10^{-7} \mathrm{~m} \mathrm{~s}^{-1}$ (Bear, 1972). Initial diffusion flux was calculated based on Fick's First Law, and ranged between $10^{1}$ to $10^{2} \mathrm{~g} \mathrm{~m}^{-2} \mathrm{y}^{-1}$.

\subsection{Discussion}

The presence of high TOC concentrations and lack of water circulation in the deeper part of the oxbow lake (hypolimnion) contributes to the development of anoxic conditions that favor the desorption of As from FeOOH (e.g. McArthur et al., 2004). Ghosh et al. (2015) reported TOC concentrations of $0.7 \%$ in clay plug deposits at shallow depths (6-12 $\mathrm{m})$ in a meandering river geomorphology in Haringhata (Nadia district, West Bengal, India). Advection and diffusion are two processes of As movement from clay plug to point bar. In case of gravitational, compaction-driven expulsion of pore fluid movement, advection occurs while the difference in concentration creating gradient favors diffusion. The hydraulic conductivity is linearly related to the diffusion flux.

\section{CONCLUSIONS}

Sediment volume of clay plugs in the floodplain along the present-day Ganges River, as calculated from remote sensing data, range from $10^{6}$ to $10^{8} \mathrm{~m}^{3}$. Arsenic concentrations from borehole data in Holocene clay plugs in West Bengal allowed for the estimate of As volume in each of the studied clay plugs. The As content ranges from $10^{5}$ to $10^{6} \mathrm{~kg}$ per clay plug. Based on Fick's First Law the initial diffusion flux was calculated and ranges from 10 to $10^{2} \mathrm{~g} \mathrm{~m}^{-2} \mathrm{yr}^{-1}$. The results of this study are crucial for the dynamic flow modelling of As-contaminated aquifers in the affected areas, and helps to develop guidelines for the location of safe, As-free groundwater extraction.

\section{ACKNOWLEDGEMENTS}

Financial support for this study from the NWOWOTRO research program "Urbanising Deltas of the World" (UDW) is gratefully acknowledged.

\section{REFERENCES}

Bear, J. 1972. Dynamics of fluids in porous media. Elsevier, New York, USA.

Donselaar, M.E., Bhatt, A.G. \& Ghosh, A.K. 2016. On the relation between fluvio-deltaic flood basin geomorphology and the wide-spread occurrence of arsenic pollution in shallow aquifers. Sci. Total Environ. 574: 901-913.

Ghosh, D., Routh, J., Dario, M. \& Bhadury, P. 2015. Elemental and biomarker characteristics in a Pleistocene aquifer vulnerable to arsenic contamination in the Bengal Delta Plain, India. Appl. Geochem. 61: 87-98.

McArthur, J.M., Banerjee, D.M., Hudson-Edwards, K.A., Mishra, R., Purohit, R., Ravenscroft, P., Cronin, A., Howarth, R.J., Chatterjee, A., Talukder, T., Lowry, D., Houghton, S. \& Chadha, D.K. 2004. Natural organic matter in sedimentary basins and its relation to arsenic in anoxic groundwater: the example of West Bengal and its worldwide implications. Appl. Geochem. 19: 1255-1293. 